\title{
Demographic, Clinical and Biochemical Characteristics of Drug Naive Type 2 Diabetes Patients of Bangladesh
}

\author{
Shahjada Selim 1*, Masud-Un Nabi², Mohammad Saifuddin'3 , Mohammad Abdul Hannan", \\ Muhammed Abu Bakar5, Samir Kumar Talukder6, A. B. M. Kamrul Hasan7, \\ Mohammad Nurul Amin', Md. Azizul Hoque9, Md. Shahinur Rahman'10, Ahmed Salam Mir'11, \\ Faria Afsana12
}

\author{
${ }^{1}$ Department of Endocrinology, Bangabandhu Sheikh Mujib Medical University, Dhaka, Bangladesh \\ ${ }^{2}$ Department of Endocrinology, Rajshahi Medical College, Rajshahi, Bangladesh \\ ${ }^{3}$ Diabetes \& Endocrinology, Dhaka Medical College, Dhaka, Bangladesh \\ ${ }^{4}$ Department of Endocrinology, North East Medical College \& Hospital, Sylhet, Bangladesh \\ ${ }^{5}$ Department of Endocrinology, Chattogram Maa O Shishu Hospital, Chattogram, Bangladesh \\ ${ }^{6}$ Department of Endocrinology, Rangpur Medical College, Rangpur, Bangladesh \\ ${ }^{7}$ Department of Endocrinology, Mymensingh Medical College, Mymensingh, Bangladesh \\ ${ }^{8}$ Department of Endocrinology, Mugda Medical College, Dhaka, Bangladesh \\ ${ }^{9}$ Endocrinology, Shaheed Ziaur Rahman Medical College, Bogura, Bangladesh \\ ${ }^{10}$ Department of Diabetes and Endocrinology, Pabna Diabetic Association Hospital, Pabna, Bangladesh \\ ${ }^{11}$ Department of Endocrinology, Bangladesh Institute of Health Sciences, Dhaka, Bangladesh \\ ${ }^{12}$ Department of Endocrinology, BIRDEM, Dhaka, Bangladesh \\ Email: *selimshahjada@bsmmu.edu.bd
}

How to cite this paper: Selim, S., Nabi, M.-U., Saifuddin, M., Hannan, M.A., Bakar, M.A., Talukder, S.K., Hasan, A.B.M.K., Amin, M.N., Hoque, M.A., Rahman, M.S., Mir, A.S. and Afsana, F. (2021) Demographic, Clinical and Biochemical Characteristics of Drug Naive Type 2 Diabetes Patients of Bangladesh. Open Journal of Endocrine and Metabolic Diseases, 11, 145-154.

https://doi.org/10.4236/ojemd.2021.118012

Received: April 23, 2021

Accepted: August 15, 2021

Published: August 18, 2021

\begin{abstract}
Background: Although the frequencies of getting drug naive type 2 diabetes patients among all the diabetic patients are very low, nowadays it claims more attention in the treatment procedures of drug naive diabetic patients. But in Bangladesh, we have very few research-oriented data regarding the demographic, clinical and biochemical characteristics of drug naive type 2 diabetes patients. The aim of this study was to determine the demographic clinical and biochemical characteristics of drug naive type 2 diabetes patients of Bangladesh. Methods: This was an open label observational real-life study which was conducted in the chambers of the investigators in several places of Bangladesh as outdoor setting during the period from August 2020 to December 2020. In total, 250 patients with drug naive type 2 diabetes mellitus were enrolled as the study population. Proper written consents were taken from all the participants before starting data collection. A pre-designed questionnaire was used in patient data collection. All data were processed, analyzed and disseminated by MS Office and SPSS version as per need. Result: Two hun-
\end{abstract}


Copyright (C) 2021 by author(s) and Scientific Research Publishing Inc. This work is licensed under the Creative Commons Attribution International License (CC BY 4.0).

http://creativecommons.org/licenses/by/4.0/ dred and fifty (250) participants were selected as study population. The male-female ratio of the participants was 1.4:1. The highest number of participants was from 51 - 60 years' age group (31.20\%). The highest number of participants (41\%) was with overweight (BMI: $25-30 \mathrm{~kg} / \mathrm{m}^{2}$ ). Majority (65\%) of the patients of this study suffered from diabetes for $\leq 5$ years. The mean $( \pm$ SD) SBP of the participants was $137.25 \pm 17.50 \mathrm{mmHg}$ and the mean $( \pm \mathrm{SD})$ DBP of the participants was $85.16 \pm 13.39 \mathrm{mmHg}$. We found the mean $( \pm \mathrm{SD})$ fasting blood sugar $(\mathrm{mg} / \mathrm{dl})$, post prandial blood sugar $(\mathrm{mg} / \mathrm{dl})$, total cholesterol ( $\mathrm{mg} / \mathrm{dl})$, triglycerides $(\mathrm{mg} / \mathrm{dl})$, HDL-Cholesterol (mg/dl), LDL-cholesterol $(\mathrm{mg} / \mathrm{dl})$, VLDL-cholesterol $(\mathrm{mg} / \mathrm{dl})$, uric acid $(\mathrm{mg} / \mathrm{dl})$, creatinine $(\mathrm{mg} / \mathrm{dl})$, urea $(\mathrm{mg} / \mathrm{dl})$, total bilirubin $(\mathrm{mg} / \mathrm{dl})$, direct bilirubin $(\mathrm{mg} / \mathrm{dl})$, SGOT $(\mathrm{IU} / \mathrm{L})$ and SGPT (IU/L) were $251.51 \pm 112.08,349.72 \pm 128.68,219.59 \pm 68.25$, $196.44 \pm 94.34,35.14 \pm 11.85,145.72 \pm 64.33,40.88 \pm 18.12,3.45 \pm 1.51,0.86$ $\pm 0.37,29.16 \pm 9.81,0.87 \pm 0.4,0.48 \pm 0.4,37.15 \pm 10.9$ and $35.83 \pm 23.04$ respectively. Conclusion: Obesity and hypertension demand more attention of diabetologists in diagnosis and treatment of patients or suspected patients of diabetes. Patients aged $\geq 50$ years are most vulnerable and suspicious for diabetes. Besides age consequence habits of tobacco smoking, family history, smoking and HTN, alcohol intake and presence of nitrites in the urine may be considered as the most potential comorbidities for diabetic patients. Diagnosis of demographic, clinical and biochemical characteristics of drug naive type 2 diabetes patients may play a vital role in proper treatment.

\section{Keywords}

Demographic, Biochemical, Clinical Characteristics, Drug Naive Type 2 Diabetes, Bangladesh

\section{Introduction}

Diabetes may be a growing drawback worldwide, significantly in developing countries wherever rates have skyrocketed. In keeping with the International diabetes disorder Federation (IDF), of the 382 million individuals with diabetes disorder (a range expected to be nearly double by 2035), a staggering eightieth board developing countries, that area unit least equipped to trot out this rising crisis. The region presumably to expertise the most force of the epidemic is South East Asia, wherever diabetes disorder is predicted to extend by seventy-one inside successive twenty-five years [1]. Bangladesh is among the highest 10 countries globally in terms of diabetes disorder burden with increasing prevalence of diabetes disorder in each urban and rural areas [2] [3]. In South Asia, the majority of diabetes disorder cases are the unit kind of type two diabetes disorder (T2D). The South Asian population presents with variety of various risk factors for T2D because of a mixture of many genetic and environmental factors [4]. A recent survey showed that diabetes disorder has become epidemic among the adult Bangladeshi population and also the prevalence of this disorder and pre-diabetes was $100 \%$ and twenty third severally [5]. The prevalence of that 
disorder was nearly double in urban compared to rural areas $(15.2 \%$ and $8.3 \%$, respectively); diabetes patients were older, had considerably a lot of cardiovascular disease and fat compared to those while not [5]. In Bangladesh, as in different countries, T2D is related to high body mass index (BMI), central fat, which may be a risk issue for each vessel diseases (CVD) and diabetes [6] [7]. The CVD risk which will be attributed to diabetes is even a lot of distinguished among South Asians than in different populations [8]. Above all, cardiovascular disease and diabetes worsen each other and together will dramatically increase the speed of complications [9]. Previous studies have shown that diabetes will increase the prevalence of dyslipidemia by a minimum of 2 -fold conjointly resulting in CVD [10]. Secondary complications of diabetes begin early and progress chop-chop among South Asians which will be reduced considerably through early detection and adequate management [11]. Metformin is the pharmacologic treatment for type 2 diabetes [12]. Glucophage acts in the main by reducing viscus aldohexose production via inhibition of gluconeogenesis [12] [13] and conjointly will increase aldohexose uptake in peripheral tissue [13]. Glucophage is related to a coffee risk of hypoglycaemia and is weight neutral or will cause weight loss [12]. However, as type 2 diabetes disorder progresses, Glucophage monotherapy typically fails to keep up glycemic management [14]. SGLT2 inhibitors act by reducing urinary organ aldohexose biological process, thereby increasing urinary aldohexose excretion and reducing symptom [15]. Empagliflozin may be a potent and selective SGLT2 mattet [16]. Most of the aldohexose by the urinary organ is reabsorbed by the $\mathrm{Na}$ aldohexose cotransporter two (SGLT2) [17]. Once used as associate add-on to Glucophage in patients with type 2 diabetes, empagliflozin (10 $\mathrm{mg}$ and $25 \mathrm{mg}$ ) significantly reduced $\mathrm{HbAlc}$, fast plasma aldohexose (FPG), and weight and was well tolerated, with a coffee risk of hypoglycaemia [18]. This study is undertaken to see the demographic and clinical characteristics of Drug Naive type 2 diabetes Patients of Bangladesh comparison the efficacy and safety of combos of Empagliflozin and Glucophage immediate unharness (IR), Vildagliptin and Glucophage with Glucophage IR monotherapy in patients with type 2 diabetes disorder.

\section{Methodology \& Materials}

This was an open label observational real-life study which was conducted in the chambers of the investigators in several places of Bangladesh as outdoor setting during the period from August 2020 to December 2020. In total 250 patients with drug naive type 2 diabetes mellitus were enrolled as the study population. According to the Standard of Care of American Diabetes Association 2021 study defined drug naive type 2 diabetes mellitus [19]. Proper written consents were taken from all the participants before starting data collection. A pre-designed questionnaire was used in patent data collection. According to the exclusion criteria of this study patients with type $1 \mathrm{DM}$, history of urinary tract infection more than 3 times in last 12 months, patient with history of recent (in last 3 months) genital mycotic infection and pregnant \& women of child bearing po- 
tential who are planning for pregnancy were excluded. Patients have been assessed for ensuring the eligibility criteria by the investigator. Detailed medical history with baseline laboratory levels, clinical evaluations, and medicine information in predefined questioner format (Patient file). Standard prescription with medicine names and dosage recommendation. Patients came in a follow up visit after one week. The investigator gave suggestion to patients regarding disease and medication (If any). Two follow up visits have been done at 3 months interval. The patients have been asked to perform some predefined laboratory test and bring those results in subsequent follow up visit. Subjects would have been given a diary. In between the three months if patient feel any Adverse Events (AE) they recorded it. For any Adverse Events they would ask to inform the respective Investigator directly or over phone. Investigator also suggested the patients over phone or if necessary, can ask the patient for a chamber visit. Patients have been given a reminder by the health staffs 1 day before the schedule visit. In 2nd visit (after 3 months) patients came to the chamber for follow up with the reports of the advised laboratory investigations. The reports recorded along with clinical assessment and diary card assessment in the patient specific questioner. The 3 rd visit was conducted after 3 months of the 2 nd visit (6 month after the enrolment). The same process has been applied for all patients by respective investigator. Each investigator handled 8 ( 8 for each arm, $8 \times 3=24$ in total) patients and there will be 14 investigators so total 50 patients' data has been generated. Safety end points included clinical laboratory parameters and adverse events (AEs), with preferred terms coded according to the Medical Dictionary for Drug Regulatory Activities (MedDRA) version 23.0. AEs included all events with an onset after the first dose and up to 7 days after the last dose of trial medication. Confirmed hypoglycemic AEs, defined as AEs with plasma glucose, $70 \mathrm{mg} / \mathrm{dL}(3.9 \mathrm{mmol} / \mathrm{L})$ and/or requiring assistance, were identified by direct plasma glucose measurements and by home blood glucose monitoring performed by the patient. Other predefined AEs of special interest included events consistent with urinary tract infection (UTI), genital infection, and volume depletion, identified using prospectively defined search categories based on 67,87 , and 8 MedDRA preferred terms, respectively. AEs related to increased urination were assessed based on a post hoc search for the MedDRA preferred terms pollakiuria, polyuria, and nocturia. Data analyzed by computer with the help of SPSS (Statistical Package for Social Science). Statistical analyses have been done by using appropriate statistical tool like "chi-square" test, student's " $T$ " test, where applicable. Statistical significance is set at 0.05 level and confidence interval at $95 \%$ level. Data has been presented in the form of table and graphs.

\section{Result}

In this study, 250 participants were selected as study population. Among them $53 \%(\mathrm{n}=133)$ were male whereas $47 \%(\mathrm{n}=117)$ were female (Figure 1$)$. So, male was dominating in number and the male-female ratio was 1.4:1. In this study in analyzing the ages of the participants we observed, the highest number 


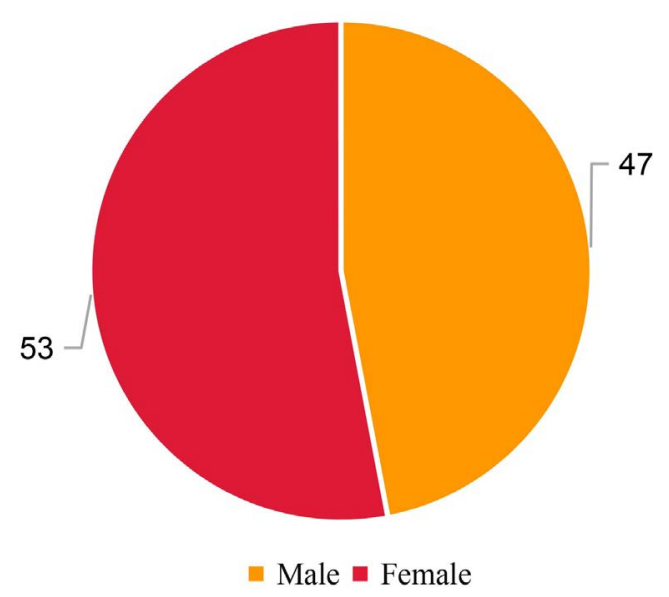

Figure 1. Sex distribution of the participants $(n=250)$.

of participants were from 51 - 60 years' age group which was $31.20 \%$. Besides this $1.20 \%, 9.20 \%, 12.80 \%, 22.00 \%$ and $23.60 \%$ were from $\geq 20,21-30,31-40$, 41 - 50 and $>60$ years' age groups respectively. Among all the participants of this study the highest number of participants were with overweight (BMI: 25 - 30 $\mathrm{kg} / \mathrm{m}^{2}$ ) which was found in $40.80 \%$. Then $34 \%$ were obese (BMI: $>30$ ) and the rest $25.20 \%$ were with normal BMI $\left(<25 \mathrm{~kg} / \mathrm{m}^{2}\right)$ (Table 1$)$. The highest number of patients of this study suffered from diabetes for $\leq 5$ years which was $65 \%(\mathrm{n}=$ 162) whereas $35 \%$ patients suffered for more than 5 years which was $35 \%$ (Figure 2). In this study, $38 \%$ participants were with hypertension. In analyzing the systolic blood pressure of the participants, we observed, the highest number of participants were with normal SBP which was found among $35.20 \%$ participants. Then $26.80 \%, 24.80 \%$ and $13.20 \%$ were with pre HTN (120 - 139), HTN, Stage 1 $(140$ - 159) and HTN, Stage $2(160)$ SBP. The mean $( \pm$ SD) SBP of the participants was $137.25 \pm 17.50 \mathrm{mmHg}$. On the other hand, in analyzing the diastolic blood pressure of the participants, we observed, the highest number of participants were with normal DBP which was found among $36.40 \%$ participants. Then $26.80 \%, 24.80 \%, 13.20 \%$ were with pre HTN (80 - 89), HTN, Stage 1 (90 - 99) and HTN, Stage $2(100)$ DBP. The mean $( \pm$ SD) DBP of the participants was fond $85.16 \pm 13.39 \mathrm{mmHg}$ (Table 2). In analyzing the biochemical status of the participants, we found the mean $( \pm \mathrm{SD})$ fasting blood sugar $(\mathrm{mg} / \mathrm{dl})$, post prandial blood sugar (mg/dl), Total cholesterol (mg/dl), triglycerides (mg/dl), HDL-cholesterol (mg/dl), LDL-cholesterol (mg/dl), VLDL-cholesterol (mg/dl), uric acid (mg/dl), creatinine $(\mathrm{mg} / \mathrm{dl})$, urea $(\mathrm{mg} / \mathrm{dl})$, Total bilirubin $(\mathrm{mg} / \mathrm{dl})$, direct bilirubin $(\mathrm{mg} / \mathrm{dl})$, SGOT (IU/L) and SGPT (IU/L) were $251.51 \pm 112.08,349.72 \pm 128.68,219.59 \pm$ $68.25,196.44 \pm 94.34,35.14 \pm 11.85,145.72 \pm 64.33,40.88 \pm 18.12,3.45 \pm 1.51$, $0.86 \pm 0.37,29.16 \pm 9.81,0.87 \pm 0.4,0.48 \pm 0.4,37.15 \pm 10.9$ and $35.83 \pm 23.04$ respectively (Table 3 ). In analyzing the comorbidities among the participants, we found in $54.80 \%, 30.80 \%, 28.80 \%, 18.80 \%, 4.40 \%$ and $8.80 \%$ participants aged $\geq 50$ years, tobacco smoking, family history, smoking \& HTN, habit of alcohol intake and nitrites in the urine were the noticeable comorbidities respectively (Table 4). 
Table 1. Age and BMI distribution of participants $(n=250)$.

\begin{tabular}{ccc}
\hline Age Distribution & $\mathbf{n}=\mathbf{2 5 0}$ & $\%$ \\
\hline$\geq 20$ years & 3 & 1.20 \\
21 years -30 years & 23 & 9.20 \\
31 years - 40 years & 32 & 12.80 \\
41 years -50 years & 55 & 22.00 \\
51 years -60 years & 78 & 31.20 \\
$>60$ years & 59 & 23.60 \\
BMI $\left(\mathrm{Kg} / \mathrm{m}^{2}\right)$ & & \\
Normal $(<25)$ & 63 & 25.20 \\
Overweight $(25-30)$ & 102 & 40.80 \\
Obese $(>30)$ & 85 & 34.00 \\
\hline
\end{tabular}

Table 2. Distribution of systolic BP and diastolic BP among participants $(\mathrm{n}=250)$.

\begin{tabular}{|c|c|c|}
\hline Systolic BP (mmHg) & $\mathrm{n}=\mathbf{2 5 0}$ & $\%$ \\
\hline Normal $(<120)$ & 88 & 35.20 \\
\hline Pre htn $(120$ - 139) & 67 & 26.80 \\
\hline Htn, stage $1(140-159)$ & 62 & 24.80 \\
\hline Htn, stage $2(160)$ & 33 & 13.20 \\
\hline Mean $( \pm s d)$ & \multicolumn{2}{|c|}{$137.25 \pm 17.50$} \\
\hline \multicolumn{3}{|l|}{ Diastolic BP (mmHg) } \\
\hline Normal $(<120)$ & 91 & 36.40 \\
\hline Pre htn $(120$ - 139) & 71 & 28.40 \\
\hline Htn, stage $1(140-159)$ & 58 & 23.20 \\
\hline Htn, stage $2(160)$ & 30 & 12.00 \\
\hline Mean $( \pm s d)$ & \multicolumn{2}{|c|}{$85.16 \pm 13.39$} \\
\hline
\end{tabular}

\section{Duration of Diabetes}

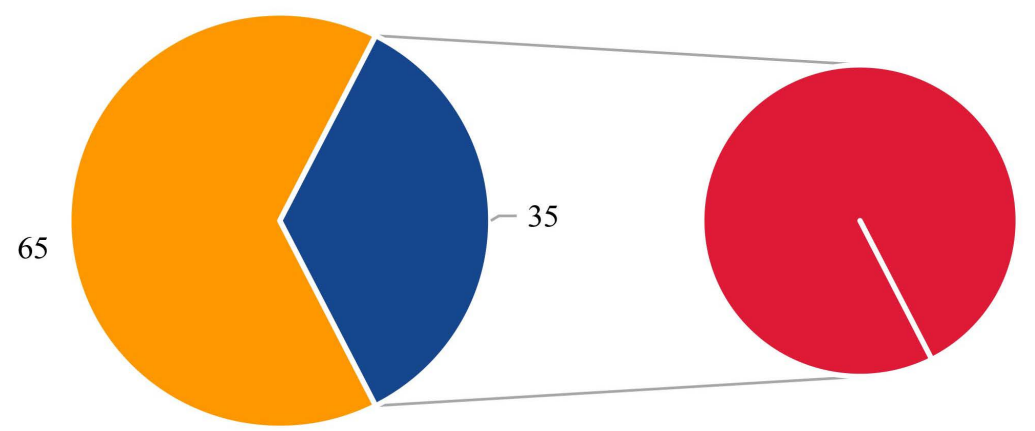

$$
\square \leq 5 \text { Years } \square>5 \text { Years }
$$

Figure 2. Duration of diabetes among the participants $(n=250)$. 
Table 3. Biochemical status of the participants $(n=250)$.

\begin{tabular}{cc}
\hline Characteristics & Mean \pm SD \\
\hline Fasting Blood Sugar $(\mathrm{mg} / \mathrm{dl})$ & $251.51 \pm 112.08$ \\
Post Prandial Bl. Su. $(\mathrm{mg} / \mathrm{dl})$ & $349.72 \pm 128.68$ \\
Total cholesterol $(\mathrm{mg} / \mathrm{dl})$ & $219.59 \pm 68.25$ \\
Triglycerides $(\mathrm{mg} / \mathrm{dl})$ & $196.44 \pm 94.34$ \\
HDL-Cholesterol $(\mathrm{mg} / \mathrm{dl})$ & $35.14 \pm 11.85$ \\
LDL-Cholesterol $(\mathrm{mg} / \mathrm{dl})$ & $145.72 \pm 64.33$ \\
VLDL-Cholesterol $(\mathrm{mg} / \mathrm{dl})$ & $40.88 \pm 18.12$ \\
Uric acid $(\mathrm{mg} / \mathrm{dl})$ & $3.45 \pm 1.51$ \\
Creatinine $(\mathrm{mg} / \mathrm{dl})$ & $0.86 \pm 0.37$ \\
Urea $(\mathrm{mg} / \mathrm{dl})$ & $29.16 \pm 9.81$ \\
Total Bilirubin $(\mathrm{mg} / \mathrm{dl})$ & $0.87 \pm 0.4$ \\
Direct Bilirubin $(\mathrm{mg} / \mathrm{dl})$ & $0.48 \pm 0.4$ \\
SGOT (IU/L) & $37.15 \pm 10.9$ \\
SGPT (IU/L) & $35.83 \pm 23.04$ \\
\hline
\end{tabular}

Table 4. Comorbidities among participants $(n=250)$.

\begin{tabular}{cc}
\hline Comorbidities & $\mathbf{n}(\%)$ \\
\hline Patient aged $\geq 50$ years & $137(54.80)$ \\
Tobacco smoking & $77(30.80)$ \\
Family history & $72(28.80)$ \\
Smoking and HTN & $47(18.80)$ \\
Alcohol intake & $11(4.40)$ \\
Nitrites in the urine & $22(8.80)$ \\
\hline
\end{tabular}

\section{Discussion}

The aim of this study was to determine the demographic clinical and biochemical characteristics of drug naive type 2 diabetes patients of Bangladesh. In this current study the male-female ratio of the participants was 1.4:1. The highest number of participants was from 51 - 60 years' age group (31.20\%). The highest number of participants (41\%) was with overweight (BMI: $25-30 \mathrm{~kg} / \mathrm{m}^{2}$ ). Majority $(65 \%)$ of the patients of this study suffered from diabetes for $\leq 5$ years. The highest number (35\%) of participants were with normal SBP where the mean $( \pm$ SD) SBP of the participants was $137.25 \pm 17.50 \mathrm{mmHg}$. On the other hand, the highest number (36\%) of participants were with normal DBP where the mean $( \pm \mathrm{SD}) \mathrm{DBP}$ of the participants was $85.16 \pm 13.39 \mathrm{mmHg}$. In analyzing the comorbidities among the participants, we found in $54.80 \%, 30.80 \%, 28.80 \%, 18.80 \%$, $4.40 \%$ and $8.80 \%$ participants aged $\geq 50$ years, tobacco smoking, family history, smoking \& HTN, habit of alcohol intake and nitrites in the urine were the noti- 
ceable comorbidities respectively. The diabetes epidemic in South Asian countries as well as Bangladesh is related to many risk factors as well as genetic predisposition, unhealthy diet, life-style and different environmental factors [20]. A study among materialistic population in Dhaka found age and case history of diabetes disorder to be considerably related to diabetes disorder [21]. The study reportable that V-day of patients with diabetes disorder were forty years or below that is analogous to our findings ( $15.3 \%$ below forty years) and implies that diabetes disorder starts at a way younger age within the Bangladeshi population compared to, e.g., European countries [22]. This finding regarding the age distribution of our study was supported by various other studies as well, supporting the fact that DM is a disease of middle-aged adults [23]. Hypertension is very important comorbid of type 2 DM. In our study, 38\% of type 2 DM patients had concomitant hypertension. Various studies found the prevalence of hypertension in type $2 \mathrm{DM}$ patients in the range of $33 \%$ to $54 \%$ [23]. Obesity is strongly related with diabetes. Our study population had a very high prevalence of obesity. Approximately $34 \%$ of our study population had a high BMI (cut-off BMI > $27 \mathrm{~kg} / \mathrm{m}^{2}$ for obese). A study found elevated BMI in $42 \%$ of type $2 \mathrm{DM}$ patients, which was comparable to our study [22]. Another study identified elevated BMI in $21 \%$ of type $2 \mathrm{DM}$ patients [24]. Another study determined central obesity in $58 \%$ of type $2 \mathrm{DM}$ patients [23]. However, another study found that $72 \%$ of type 2 DM patients had high WHR [24]. Various other studies also found similar results [25]. In analyzing the comorbidities among the participants, we found in $54.80 \%, 30.80 \%, 28.80 \%, 18.80 \%, 4.40 \%$ and $8.80 \%$ participants aged $\geq 50$ years, tobacco smoking, family history, smoking \& HTN, habit of alcohol intake and nitrites in the urine were the noticeable comorbidities respectively.

\section{Limitations of the Study}

This was an observational study with a small sized sample. So, the findings of this study may not reflect the exact scenario of the whole country.

\section{Conclusion and Recommendations}

Obesity and hypertension demand more attention of diabetologists in diagnosis and treatment of patients or suspected patients of diabetes. Patients aged $\geq 50$ years are most vulnerable and suspicious for diabetes. Besides age consequence habits of tobacco smoking, family history, smoking and HTN, alcohol intake and presence of nitrites in the urine may be considered as most potential comorbidities for diabetic patients. Diagnosis of biochemical characteristics of such patients may play a vital role in proper treatment. For getting more reliable information, we would like to recommend for conducting more studies in several places with larger sized samples.

\section{Conflicts of Interest}

The authors declare no conflicts of interest regarding the publication of this paper. 


\section{References}

[1] Guariguata, L., Whiting, D.R., Hambleton, I., Beagley, J., Linnenkamp, U. and Shaw, J.E. (2013) Global Estimates of Diabetes Prevalence for 2013 and Projections for 2035. Diabetes Research and Clinical Practice, 103, 137-149. https://doi.org/10.1016/j.diabres.2013.11.002

[2] Whiting, D.R., Guariguata, L., Weil, C. and Shaw, J. (2011) IDF Diabetes Atlas: Global Estimates of the Prevalence of Diabetes for 2011 and 2030. Diabetes Research and Clinical Practice, 94, 311-321. https://doi.org/10.1016/j.diabres.2011.10.029

[3] Hussain, A., Rahim, M., Azad Khan, A., Ali, S. and Vaaler, S. (2005) Type 2 Diabetes in Rural and Urban Population: Diverse Prevalence and Associated Risk Factors in Bangladesh. Diabetic Medicine, 22, 931-936. https://doi.org/10.1111/j.1464-5491.2005.01558.x

[4] Swaminathan, K., Mathavan, A. and Jebamani, S. (2013) Diabetes and Coronary Artery Disease in South Asians. The British Journal of Diabetes \& Vascular Disease, 13, 124-129. https://doi.org/10.1177/1474651413492177

[5] Akter, S., Rahman, M.M., Abe, S.K. and Sultana, P. (2014) Prevalence of Diabetes and Prediabetes and Their Risk Factors among Bangladeshi Adults: A Nationwide Survey. Bulletin of the World Health Organization, 92, 204-213. https://doi.org/10.2471/BLT.13.128371

[6] Bhowmik, B., Munir, S.B., Ahmed, K.R., Siddiquee, T., Diep, L.M., Wright, E., et al. (2013) Anthropometric Indices of Obesity and Type 2 Diabetes in Bangladeshi Population: Chandra Rural Diabetes Study (CRDS). Obesity Research \& Clinical Practice, 8, e220-e229. https://doi.org/10.1016/j.orcp.2013.06.001

[7] Rahim, M., Hussain, A., Azad Khan, A., Sayeed, M.A., Keramat Ali, S. and Vaaler, S. (2007) Rising Prevalence of Type 2 Diabetes in Rural Bangladesh: A Population-Based Study. Obesity Research \& Clinical Practice, 77, 300-305.

https://doi.org/10.1016/j.diabres.2006.11.010

[8] Ramachandran, A., Mary, S., Yamuna, A., Murugesan, N. and Snehalatha, C. (2008) High Prevalence of Diabetes and Cardiovascular Risk Factors Associated with Urbanization in India. Diabetes Care, 31, 893-898. https://doi.org/10.2337/dc07-1207

[9] Jandeleit-Dahm, K. and Cooper, M.E. (2002) Hypertension and Diabetes. Current Opinion in Nephrology and Hypertension, 11, 221-228.

https://doi.org/10.1097/00041552-200203000-00014

[10] Waeber, F.F. and Luis Ruilope, B. (2001) Diabetes and Hypertension. Blood Pressure, 10, 311-321. https://doi.org/10.1080/080370501753400610

[11] Leung, G. and Lam, K. (2000) Diabetic Complications and Their Implications on Health Care in Asia. Hong Kong Medical Journal, 6, 61-68.

[12] Hundal, R.S., Krssak, M., Dufour, S., et al. (2000) Mechanism by Which Metformin Reduces Glucose Production in Type 2 Diabetes. Diabetes, 49, 2063-2069. https://doi.org/10.2337/diabetes.49.12.2063

[13] Basu, R., Shah, P., Basu, A., et al. (2008) Comparison of the Effects of Pioglitazone and Metformin on Hepatic and Extra-Hepatic Insulin Action in People with Type 2 Diabetes. Diabetes, 57, 24-31. https://doi.org/10.2337/db07-0827

[14] Turner, R.C., Cull, C.A., Frighi, V., Holman, R.R. and UK Prospective Diabetes Study (UKPDS) Group (1999) Glycemic Control with Diet, Sulfonylurea, Metformin, or Insulin in Patients with Type 2 Diabetes Mellitus: Progressive Requirement for Multiple Therapies (UKPDS 49). JAMA, 281, 2005-2012. 
https://doi.org/10.1001/jama.281.21.2005

[15] Miccoli, R., Penno, G. and Del Prato, S. (2011) Multidrug Treatment of Type 2 Diabetes: A Challenge for Compliance. Diabetes Care, 34, S231-S235.

https://doi.org/10.2337/dc11-s235

[16] DeFronzo, R.A., Eldor, R. and Abdul-Ghani, M. (2013) Pathophysiologic Approach to Therapy in Patients with Newly Diagnosed Type 2 Diabetes. Diabetes Care, 36, S127-S138. https://doi.org/10.2337/dcS13-2011

[17] Gallo, L.A., Wright, E.M. and Vallon, V. (2015) Probing SGLT2 as a Therapeutic Target for Diabetes: Basic Physiology and Consequences. Diabetes and Vascular Disease Research, 12, 78-89. https://doi.org/10.1177/1479164114561992

[18] Grempler, R., Thomas, L., Eckhardt, M., et al. (2012) Mpagliflozin, a Novel Selective Sodium Glucose Cotransporter-2 (SGLT-2) Inhibitor: Characterization and Comparison with Other SGLT-2 Inhibitors. Diabetes, Obesity and Metabolism, 14, 83-90. https://doi.org/10.1111/j.1463-1326.2011.01517.x

[19] (2021) Classification and Diagnosis of Diabetes: Standards of Medical Care in Diabetes 2021. Diabetes Care, 44, S15-S33. https://doi.org/10.2337/dc21-S002

[20] Ramachandran, A., Snehalatha, C. and Ma, R.C.W. (2014) Diabetes in South-East Asia: An Update. Diabetes Research and Clinical Practice, 103, 231-237. https://doi.org/10.1016/j.diabres.2013.11.011

[21] Saquib, N., Khanam, M.A., Saquib, J., Anand, S., Chertow, G.M., Barry, M., et al. (2013) High Prevalence of Type 2 Diabetes among the Urban Middle Class in Bangladesh. BMC Public Health, 13, Article No. 1032. https://doi.org/10.1186/1471-2458-13-1032

[22] Khanam, P.A., Mahtab, H., Ahmed, A.U., Sayeed, M.A. and Khan, A.A. (2008) In Bangladesh Diabetes Starts Earlier Now than 10 Years Back: A BIRDEM Study. Ibrahim Medical College Journal, 2, 1-3. https://doi.org/10.3329/imcj.v2i1.2922

[23] Borah, M. and Goswami, R.K. (2017) Sociodemographic and Clinical Characteristics of a Diabetic Population at a Tertiary Care Center in Assam, India. Journal of Social Health and Diabetes, 5, 37-42.

[24] Rana, H.M., Chavda, P., Rathod, C.C. and Mavani, M. (2015) Socio-Demographic and Anthropometric Profile of Diabetic Patients Attending Diabetes Clinic in Tertiary Care Hospital of Central Gujarat. National Journal of Community Medicine, 6 , 554-557.

[25] Mayer-Davis, E.J. and Costacou, T. (2001) Obesity and Sedentary Lifestyle: Modifiable Risk Factors for Prevention of Type 2 Diabetes. Current Diabetes Reports, 1, 170-176. https://doi.org/10.1007/s11892-001-0030-x 